\title{
Innovation Risk of the Financial Derivatives in China - Taking the accumulator as an example
}

\author{
Xuan Wang \\ School of Economics and Management, Beijing Jiaotong University, Beijing, 100044, China
}

\begin{abstract}
The economic development is inseparable from the financial facilitation, and the power of financial development is from the innovation. The financial innovation becomes an important thrust of the survival and development of financial industry. With the wide application of information technology, the financial information has become a common topic in the financial industry. But in the process where the financial industry carries out financial innovation and produces positive effect, it also breaks the original balance, causing a certain degree of negative influence and thus producing financial risks. This article conducts a research by taking the complex derivative KODA (also called accumulator) as an example to interpret KODA's structure, nature and the financial risks induced thereby. It analyzes the reason for the happening of financial innovation, and meanwhile proposes corresponding advice to prevent the risks, expecting to have a conducive discussion with everyone.
\end{abstract}

Keywords. financial innovation; financial risks; accumulator; financial derivative

\section{Current situation of Chinese financial derivatives innovation and the influence of KODA}

In China, the demand of real economy on the financial innovation is increased rapidly, and the demand hierarchy is also constantly rising. Especially, the comprehensive opening of financial industry will boost the process of financial system reformation, and the wide introduction of external financial institution into Chinese financial market will directly bring the innovation business. The intensified competition will also force the domestic financial institutions to boost the innovation process. Nowadays, the financial derivative tools transaction has become the main component of business around the global banking industry. There are over 150 large business banks and securities companies in the world of which the profits are mainly from the transaction and development of derivative tools. The profits of financial institution departments established in many large financial institutions have exceeded the output of traditional departments. Therefore, the innovation and transaction of financial derivative tools in China will effectively expand the business scope of domestic financial innovations, especially of the securities institutions. The traditional and single securities issue and self-operated business for the traditional domestic securities traders will be extended to a larger innovation and transaction of derivative tools. The innovation and transaction of financial derivative tools widen the selection scope of the market investors, and largely expand the business scope of various financial institutions as well. 
Nowadays, the financial derivative tools transaction has become the main component of business around the global banking industry. It is not only an efficient risk management method for the investors, but also a speculation tools for some speculators. We can say the financial derivative is a double-edged sword. It'll work very well in the risk management field if it is used properly, otherwise it may cause serious damage or even induce permanent loss for the national economy. One of the reasons for the breakout of financial crisis in the US is that the financial derivatives were abused in the financial institutions and the government monitored the market risk improperly.

While, from 2007 to 2008, a few large state-owned enterprises, many rich men and celebrities in the mainland and Hong Kong had participated in the KODA (accumulator) investment, and they paid a heavy price in the market shortly afterwards. Citic Pacific suffered a loss of 18.6 billion yuan due to the investment in the AUD accumulator; Shennan electric, China Eastern Airlines and Air China also suffered a considerable loss due to the investment respectively in the accumulator of petroleum and aviation oil; Furthermore, the inland enterprise Country Garden participated in the investment of stock accumulator and suffered a loss of 1.2 billion yuan. The inland rick men, such as Ting Hao, an individual investor in Hong Kong DBS bank, and Jianping Lai, an individual investor in Hong Kong ABN AMRO, suffered a loss of several million yuan. What actually caused those shocking events of loss is a kind of financial derivative Accumulator, also called "financial drug", "financial opium" and "rick men killer" by the medias and some scholars. The full English name of this product is "Knock Out Discount Accumulator", simply known as KODA.

\section{Analysis on KODA's structure}

KODA product is a complex-structured financial option contract, and its subject matter can be stock, foreign exchange, petroleum and other material or financial assets. This contract generally has the following features:

(1) The contract has set an exercise price, which will be given a certain discount based on the early-stage price when the investor purchases the subject matter. Assuming the early-stage price for the subject matter is $\mathrm{S}_{0}$, the exercise price of this option is $\mathrm{S}_{0}(1-\mathrm{D})$ in which the $\mathrm{D}$ is the downward allowance ratio, generally between $10 \%-20 \%$;

(2) The contract has set a knock out price. If the market price, $S_{t}$, of the subject matter exceeds the early-stage price $S_{0}$ for a certain degree, the option contract will be automatically terminated. Assuming the allowable upward exceeding proportion is $U$, generally between $3 \%-5 \%$, the knock out price of this option will be $\mathrm{S}_{0}(1+\mathrm{U})$;

(3) If the market price of the subject matter is lower than the exercise price, the investor must purchase several-fold number of subject matters, generally twofold;

(4) This option contract has an unfixed expiry date. If the market price of the subject matter in the holding period is not more than the knock out price, the holding period of this option will be $\mathrm{T}$ (or the expiry date is T), namely the nominal expiry date is the same as the actual expiry date, generally one year. If the option is terminated in the holding period, the actual expiry date of the option will be the date when the market price of subject matter is more than the knock out price, earlier than the nominal expiry date;

(5) This option contract is generally settled in a certain cycle, which may be 1 day, 1 week or 1 month;

(6) Each contract will set a minimum amount of investment, generally not less than 1 million dollars;

(7) The investor can purchase as long as it has the cash or mortgage in a certain proportion of the contract amount, and this proportion is generally set during $30 \%$ to $50 \%$. So the KODA products are often highly leveraged;

(8) There's no option fee for the option contract in the early stage.

In the end of every settlement cycle, if the market price, $S_{t}$, of the subject matter lies between the exercise price and knock out price, the investor may purchase the subject matter, of which the 
market price is $S_{t}$, with the exercise price $S_{0}(1-D)$, and the profit is $S_{t}-S_{0}(1-D)$; If the $S_{t}$ is more than the knock out price $S_{0}(1+U)$, the profit of the investor will remain as $S_{t}-S_{0}(1-D)$, but the contract will be automatically terminated; If the $S_{t}$ is lower than the exercise price $S_{0}(1-D)$, the investor must purchase double number of subject matter with the exercise price, and the loss is $2\left(\mathrm{~S}_{0}(1-\mathrm{D})-\mathrm{S}_{\mathrm{t}}\right)$.

In view of features, this is a transaction with non-symmetrical risk and yield, and with more preference for the seller. Obviously for the investor, the profit is limited, and the loss is unlimited. But for the trader, the profit is unlimited, and the loss is limited. Even though the expectation of the investor is consistent with the market trend, the contract will be terminated in advance if the assets market price of subject matter is more than the knock out price, which invisibly sets a upper limit for the loss of private banks; But if the expectation of the investor is against the market trend, there will be no stop-loss, and what's worse, the contract clauses will further expand the loss.

\section{Nature of KODA}

Actually, the KODA contract is the combination of a series of obstacle option. Specifically, in every settlement cycle, the KODA contract may be considered as the combination of an upward knock out call option and two downward knock in call options. If an investor purchase a KODA contract, it can be deemed as purchasing an upward knock out call option at first and then selling two downward knock in call options. At the end of the settlement cycle, the profit and loss of the investor can be calculated according to the implemented option determined by the market price level of the subject matter. No matter there is a profit or loss in every settlement cycle, the investor may nevertheless purchase the subject matter with the exercise price as long as the KODA contract is valid. But in the actual calculation of profit and loss, it is only the price difference of the market price and exercise price of the subject matter that will be calculated, by which the profit and loss of the investor can be determined. And there's no real transaction about the subject matter. So this contract is actually a valuation adjustment contract which is signed between an investor and its trading competitor about the change of the market price of subject matter. The seller always remains in a favorable position in the financial derivatives with "valuation adjustment property". All the purchasers of the financial derivatives are almost not aware that they are meant to be in an unfavorable position from the beginning.

\section{Risk of KODA}

As a complex-structured derivative, the KODA will bring serious risks in the process of use due to its high leverage property. Different from the regular option trade, the accumulator issuer will devise a variety of titles to transform the high-risk investment strategy into a simple investment tool and promote it to some investors not experienced in the investment. Neglecting the risk factors is the primary reason that easily misleads the purchaser.

\subsection{Deliberately concealing the risks using the non-symmetry of information}

KODA is a kind of financial product with complex structure. Simply from the description of the contract clauses, the investor will not always be fully aware of the huge risk to be faced. With the help of strong ability in the market expectation, the banks tend to use the non-symmetry of information to fix the allowance price, exercise price and knock out price, which is key to the contract, to a level best for themselves. Firstly, the product sales will bring a significant profit; secondly, the highly complex design of product will easily produce an extreme knowledge nonsymmetry between the sales institution and the investor. This is the reason why the banks love to promote this product to get a huge profit with the help of this non-symmetry. Moreover, the product risk and profit is extremely non-symmetrical, and few of the profit have an upper limit but 
the loss is unlimited. Many investors will not invest in the product if this non-symmetry is clearly told to the investor in advance. Many investors have no professional knowledge and may be deluded by the bright future the banks describe in the promotion of the product.

\subsection{Dual role of financial advisor}

In recent years, with the emergence of some financial derivatives, the services in some banks started to be deteriorated. The financial advisor in the bank plays a dual role, not only helping the clients with financing, but also promoting the financial product to them. Based on the trust for the financial advisor, some clients will sign a KODA contract after listening to the introduction from the financial advisor. At this moment, the clients definitely will not be aware the financial advisor that used to serve them has become a promoter of high-risk derivatives, and they blindly believe in this product exaggerated by the financial advisor, thinking this is a special offer for the high-end customers from the bank. But they don't know they are being caught in a big hidden troubles. The dual identity of the bank is also an important reason for the popularity of this complex derivative similar to the accumulator.

But the investor itself shall also be responsible for most. The potential risk of KODA is neglected, and the investor only notices its profit. A majority of the investors in the bull market blindly believe that the capital market will constantly rise, but they don't realize a huge risk is approaching; Furthermore, many investors don't know clearly about the risk of the structured financial derivatives and blindly purchase those unfamiliar complex derivatives under the delusion of high profits. As in the Hong Kong market in 2005, the assets market kept a good performance, and many investors focused on how to make profits there, while never realizing the market would suddenly decline sometime. A great amount of assets were bet in the rising market, but it was too late to sell off and realize the profits when the market was actually declined. The collective sell-off of the investors might only cause further decline of the market and more serious loss. In the late 2007 , over $70 \%$ of the clients in Hong Kong private banks purchased the stocks in the form of KODA product from the issuing bank. As a result, many rick men in Hong Kong suffered a great loss in 2008 when the financial crisis happened and caused constant decline in the stock market.

\section{Risk features of the financial derivatives}

\subsection{Suddenness of risk emergence of the financial derivatives}

On one hand, as the transaction of financial derivatives is an off-balance-sheet business project that cannot be reflected in a balance sheet, the non-symmetry and incompleteness of information makes it harder for the participators in the direct market to assess the relevant risks their competitors undertake; On the other hand, the high-tech and complexity features of the financial derivatives make the established accounting system lack the standard and ability to reflect the transaction border, assess the risk, confirm the market value and disclose the financial items, which further prevent the regulatory authority from fully understanding, responding to and efficiently managing the potential risks in the financial derivatives in time. Therefore, the eruption of risks in the financial derivatives is with suddenness.

\subsection{The risks of financial derivatives have a strong expansion effect}

The development of financial derivatives break the traditional limit of the derivatives with the basic products and financial systems in various countries, thus transmitting the risks of financial derivatives to every corner of the global financial system. On one hand, the derivatives market is closely related to the currency market, foreign exchange market, stock market and other basic assets market, producing a strong mutual linkage effect among them. The financial turbulence, 
once happening in one market system, will be fast extended to another one, which intensifies the expansion and evolution degree of the crisis; On the other hand, the transaction of financial derivatives is conducted internationally and, due to the rapid evolution of modern information technology, will be developed to a degree to which most of the market participators and currency authorities in various countries are unable to make proper response. This will make the risks of financial derivatives very easy to spread and induce a wide range or even global financial crisis. Furthermore, because of the high technology, complex transaction procedure and difficult pricing features of the derivatives, only the large institutions with sufficient capital and professional technicians can be involved, which makes the credit risks concentrated on those rare institutions. In such case, a sudden bankruptcy or non-performance of one institution will induce a series of breaching events in the whole derivatives market and further cause the collapse of the financial system.

\subsection{Huge loss will be induced by the risks in the financial derivatives}

Most of the derivatives transactions will be conducted in a leverage mode. The participator may simply need a little, or even without, fund allocation to conduct a transaction with considerable amount. Furthermore, the virtuality feature of the derivatives makes many institutions originally having strong capital strength suffer a continuous loss or bankruptcy due to improper use of derivatives. So far, there are over 20 events about the substantial amount of loss induced in the derivatives transaction, generally taking the "hundred million" as the measurement unit. For instance, Barings Bank suffered a loss of 81.6 billion pounds; German Metal Group suffered a loss of 2.8 billion marks; Japan Sumitomo Trading Company suffered a loss of 2.6 billion dollars; China Aviation Oil suffered a loss of 515.4 billion dollars.

\section{Risk management strategy of the financial derivatives}

\subsection{Strengthen the legislation to create a good institutional environment for the development of financial derivatives}

(1) Formulate and perfect the laws related to financial product innovation. The financial derivative, in itself, is a constantly innovated tool, and the innovation is key to its survival and the premise for its constant development. The innovation of new product may provide a new opportunity, new transaction means and a new profit mode to facilitate the constant growth of transaction volume; (2) Formulate the laws related to the risk management of financial derivatives so that the job responsibilities, the formulation of management procedures and rules for the risk management body will be bound and guided by the corresponding laws. Formulate the laws and regulations respectively according to different types of financial derivatives, and strengthen the coordination and operability for various codes to create a good legal policy environment for the development of financial derivatives.

\subsection{Establish and perfect the risk supervisory system and supervisory setup}

The risk supervision of financial derivatives is divided into two parts, namely inner and outer supervision. Outer supervision is to prevent and control the risks in the derivatives by 3-hierarchy united supervisory system.

(1) The domestic securities supervisory authority is also a risk management organization in the highest hierarchy. In the risk supervision, the securities supervisory authority is mainly responsible for the system construction in order to create an open, fair and impartial market environment through a strict market supervision. In the risk supervision, the securities supervisory authority focuses on the irrational instinct "laying more emphasis on profits than risks" of the market 
participation bodies, non-symmetry of market information, market manipulation, client deception and other market defects in order to heighten the risk awareness for the market participators, improve the transparency of market information, prevent the market irregularities and protect the interests of investors.

(2) As a most basic management institution, it is responsible for unified supervision of the exchanges and self-regulatory trading organizations. The special role they play enables them to have an efficient impact on various participators in the market transactions to effectively limit and formalize their market behaviors.

(3) Transnational unified supervision is conducted in the combined efforts of the main domestic supervisory departments and other countries or international organizations. They jointly design and formulate the transnational supervisory mechanism and rules for the financial derivatives transaction and prevent the risks from being produced and spread beyond the sovereign jurisdiction. The inner supervision is a risk management system established by the transaction body itself. The market transaction body shall integrate the existing internal control resources and comprehensively formulate procedures for risk cognition, measurement, monitor and report in the financial derivatives market. Strengthen the internal control, strictly control the transaction procedures, separate the rights of operation, settlement and supervision, have a strictly wellarranged business authorization and increase the punishment of ultra vires transaction; establish a special risk management and supervisory department to record and confirm the transaction of traders, tentatively calculate the market value thereof, assess, measure and prevent the financial derivatives from facing various risks in the transaction process, gradually adopt the latest market risk management technology and the corresponding model to constantly monitor the risks and improve the management and control ability.

\section{Conclusion}

Even with the financial of risk transfer, but the financial derivative also presents various risks due to externality, monopoly, non-symmetry of information and other factors. Only we deepen the understanding of the risks in the financial derivative and its features, as well as in macro and micro perspective, do well in the legislative codes and system construction, establish a perfect risk supervisory system and supervisory setup, and use a proper risk macro strategy can we avoid the phenomenon of "financial opium" like KODA to efficiently prevent the risks from happening in the self-operation of financial derivatives and take advantage of its functions better.

\section{References}

1. Zhang, J. New Interpretation of Accumulator [J]. Business Condition, 2012(26): 35-35.

2. Xu, G.L., Zhao, H. Explanation of Accumulator [J]. Jiangsu Business Theory, 2009.

3. Wang, K.M., Pan, H.P., Zhou, W.J., Research on the Risk Value of Knock Out Accumulator [C]. // Annual Meeting of Management Science in China_-Branch Financial Conference Hall. 2009.

4. Zheng, Y.Y. Research on the Risks in Financial Innovation [D]. Wuhan University of Technology, 2005. DOI:10.7666/d.y812783.

5. Jin, J.P., Yang, X.M. Development of Financial Innovation and Prevention of Its Risks [J]. Zhejiang Finance, 2008(9): 31-32. DOI:10.3969/j.issn.1005-0167.2008.09.017.

6. Que, X.H., Chen, M.H. Brief Discussion on the Management of Financial Innovation and Financial Risks [J]. Economic Research Guide, 2007(7): 58-61.

7. Ren, X.M., Wang, Y. Pricing of 1-class Accumulator [J]. Commercial economy, 2012(13).

8. Zang, J. Revelation and Prevention of Risks in the Accumulator [J]. Times Finance TriMonthly, 2012(24): 255-255. 
9. Hong, F. Analysis on the Case of Investment in Foreign Exchange Accumulator for Citic Pacific [J]. Journal of Shunde Polytechnic, 2012, 10(2). DOI:10.3969/j.issn.16726138.2012.02.006. 